Supplement of Atmos. Chem. Phys., 21, 16575-16591, 2021

https://doi.org/10.5194/acp-21-16575-2021-supplement

(C) Author(s) 2021. CC BY 4.0 License.

(c) (i)
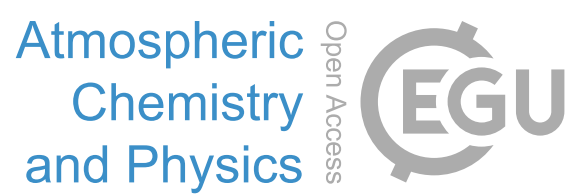

Supplement of

\title{
A weather regime characterisation of winter biomass aerosol transport from southern Africa
}

\section{Marco Gaetani et al.}

Correspondence to: Marco Gaetani (marco.gaetani@iusspavia.it)

The copyright of individual parts of the supplement might differ from the article licence. 


\section{S1. CAMS PCA analysis and class partition}

The daily variability of the atmospheric circulation over southern Africa and the South Atlantic in ASO is analysed in terms of EOFs of the geopotential height daily anomalies at $700 \mathrm{hPa}$, which show the first 2 modes accounting for $58.4 \%$ of the total variance (Fig. S1ab). The positive phase of the first EOF (which explains $31.7 \%$ of the variance) is characterised by a high pressure anomaly dominating southern Africa and a low pressure anomaly in the South Atlantic (Fig. S1a). The associated circulation anomaly is favourable to BBA transport from tropical southern Africa towards the Atlantic and a recirculation southward along the Namibian coast, while the transport from South Africa towards the Indian Ocean is inhibited (Fig. S1a). The positive phase of the second EOF (explaining $26.7 \%$ of the variance) shows a high pressure anomaly dominating the circulation over southern Africa and South Atlantic, pushing the northerly BBA recirculation westward over the South Atlantic and further weakening the transport towards the Indian Ocean (Fig. S1b). The first two EOFs explain similar variance and show similar spatial patterns shifted in the longitudinal dimension, suggesting that they form a pair in quadrature. This hypothesis is tested by computing the daily lead/lag correlation between the first PC time series (PC1) and itself, to be compared with the lead/lag correlation between PC1 and PC2 (Fig. S2). The maximum correlation between PC1 and PC2 is 0.34 at a lead time of 2 days. Synoptic centres of action in EOF1 and 2 are shifted by about $14-20^{\circ}$ in longitude (Fig. S1ab), so given the 2-day lag between the positive phase of EOF1 and 2, the apparent propagation speed is $7-10^{\circ} /$ day eastwards, i.e. $7.0-9.6 \mathrm{~m} / \mathrm{s}$ (at $40^{\circ} \mathrm{S}, 1^{\circ}$ in longitude equals $85 \mathrm{~km}$ ). Considering that the mean zonal flow at $700 \mathrm{hPa}$ in ASO in the $35-40^{\circ} \mathrm{S}$ belt in the South Atlantic is $12.8 \mathrm{~m} / \mathrm{s}$, these values are consistent with travelling Rossby waves with wave number 8-12. Therefore, these two circulation modes represent the variability associated with high-wave-number propagative disturbances along the midlatitude westerly flow (see e.g. Widlansky et al. [2011] and van der Wiel et al. [2015] for the characterisation of synoptic disturbances in southern midlatitudes). The third EOF (explaining $14.1 \%$ of the variance) is also associated with a circulation pattern resembling to a wave pattern displaced along the midlatitude mean flow, which modulates the meridional recirculation of BBA poleward (Fig S1c). The fourth EOF (explaining $8.1 \%$ of the variance) is characterised by the variability of the pressure in the South Atlantic, which modulates the midlatitude westerly flow and the westward BBA transport in the Tropics (Fig. S1d).

The first 4 EOFs, accounting for at least $80 \%$ of the total variance, are used to filter out the noise associated with the lowest rank modes from daily variability, which is then classified into circulation types by means of a k-means algorithm, using $k=[2,10]$ (Michelangeli et al., 1995). For each $k$, the classification is performed 100 times, to ensure reproducibility of the results. A red-noise test is performed to assess the significance of the class partition (Michelangeli et al., 1995), resulting in 6 and 7 classes (Fig. S3). The synoptic characterisations of the BBA transport performed by using 6 and 7 classes are presented in the main text and in following Section $\$ 2$, respectively. 

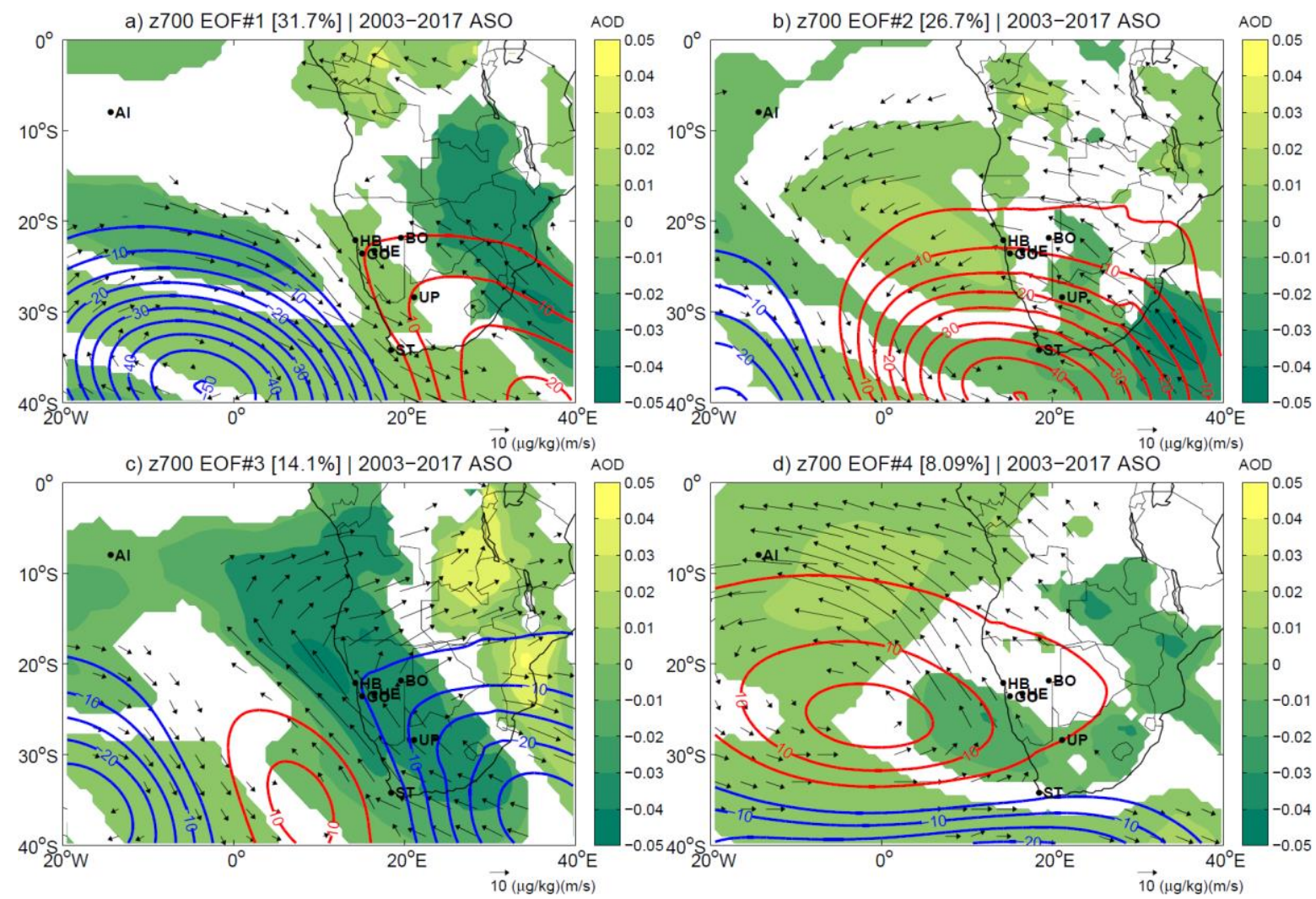

Figure S1. Anomaly patterns of CAMS geopotential height ( $\mathrm{m}$, contours), AOD at $550 \mathrm{~nm}$ (shadings) and organic matter transport $((\mu \mathrm{g} / \mathrm{kg})(\mathrm{m} / \mathrm{s})$, arrows) at $700 \mathrm{hPa}$ associated with the first to fourth EOF of the geopotential height at $700 \mathrm{hPa}$ in ASO 2003-2017 (EOF explained variance is displayed in brackets). Anomaly patterns are computed by regressing daily anomaly data onto standardised time series derived from the PCA; only values significant at $95 \%$ level of confidence are displayed. Dots indicate the locations of the AERONET stations (see Table 1 in the main text).

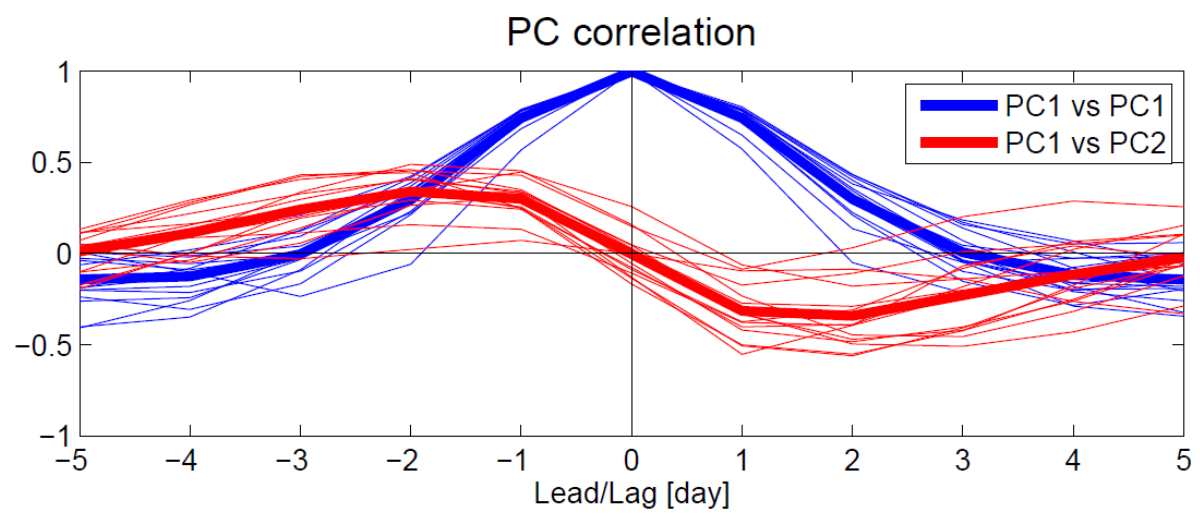

Figure S2. Daily lead/lag correlation of PC1 with itself (in blue) and PC1 with PC2 (in red): thin lines represent the correlation in individual years, thick lines represent the 2003-2017 average. 


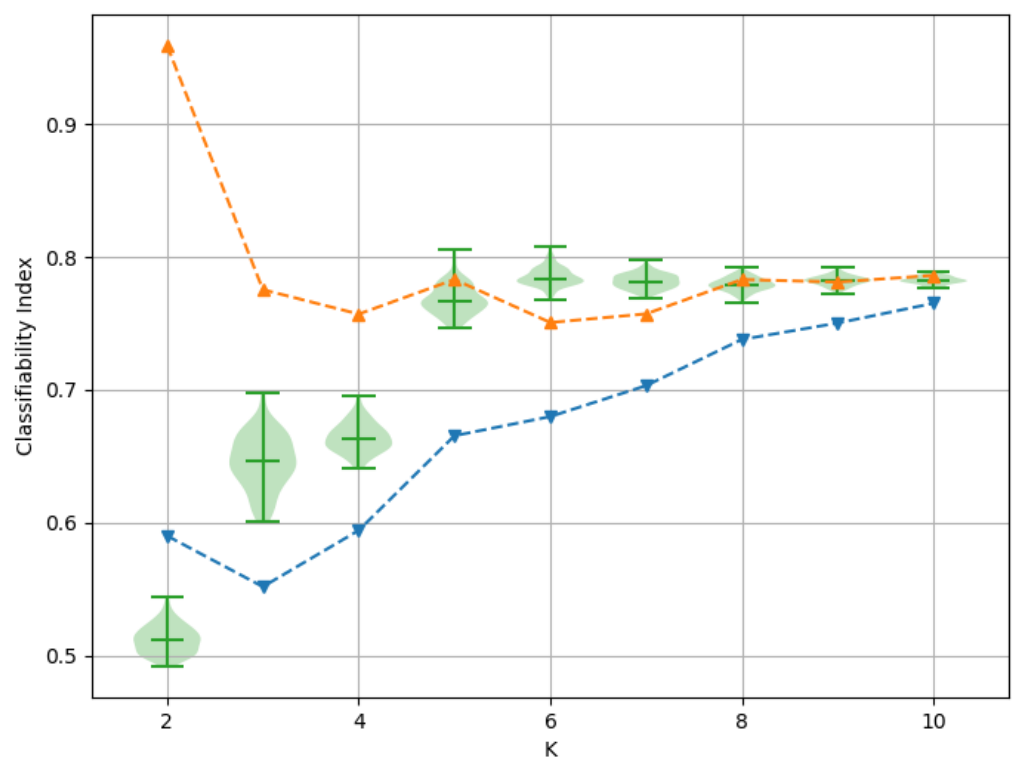

Figure S3. Spread of the classificability index (violin plots) as a function of the number of regimes (K) for 100 clusterings initialized with different random draws. The levels of significance at 5 and $95 \%$ (blue line and orange line, respectively) are computed according to a first-order Markov process (also known as "red-noise test").

\section{S2. Assessment of the CAMS 6 class partition}

The robustness of the 6 class partition described in Section S1 (referred as "control" classification, see also Sections 2.3 and 3.1 in the main text) is tested against different choices of the retained variance (at least 90\%, accounted for by the first 7 PCs, referred as "PC7" classification) and the geographical domain $\left(\left[20^{\circ} \mathrm{W}-40^{\circ} \mathrm{E}, 10^{\circ} \mathrm{S}-50^{\circ} \mathrm{S}\right]\right.$, referred as "shifted" classification). All three classifications feature two WRs characterised by shortly persistent pressure anomalies in the South Atlantic (SA+ and SA-, see Fig. S4 and S5, and Tables S1-3) and four WRs characterised by pressure anomalies transitioning into each other at midlatitudes (ML1-4, see Fig. S4 and S5, and Tables S1-3). Modifying retained variance and geographical domain does not substantially affect the circulation features of SA+, SA-, ML1 and ML3. Conversely, the synoptic patterns associated with ML2 and 4 in the "control" classification are not found in the "PC7" and "shifted" classifications. In particular, the ML2 pattern is not found in the "PC7" classification, and ML4 is not found in "shifted" (Fig. S4). Interestingly, the spurious patterns in the "PC7" and "shifted" classifications show a high degree of similarity, with similar seasonal frequencies ( $13 \%$ and $14 \%$, respectively), possibly indicating a synoptic pattern escaping the geographical and variance bounding of the "control" classification. The occurrence of 'spurious' WRs leads to differences in the transition rates (Tables S1-3) and in the seasonal frequencies (Fig. S6). More importantly, the identification of 'spurious' WRs in the "PC7" and "shifted" classifications leads to little co-occurrence of the WRs ( $54 \%$ and $49 \%$, respectively) with respect to the "control" classification. However, when the 'spurious' WRs are not considered in the co-occurrence estimation, rates increase to $72 \%$ and $65 \%$, respectively. 

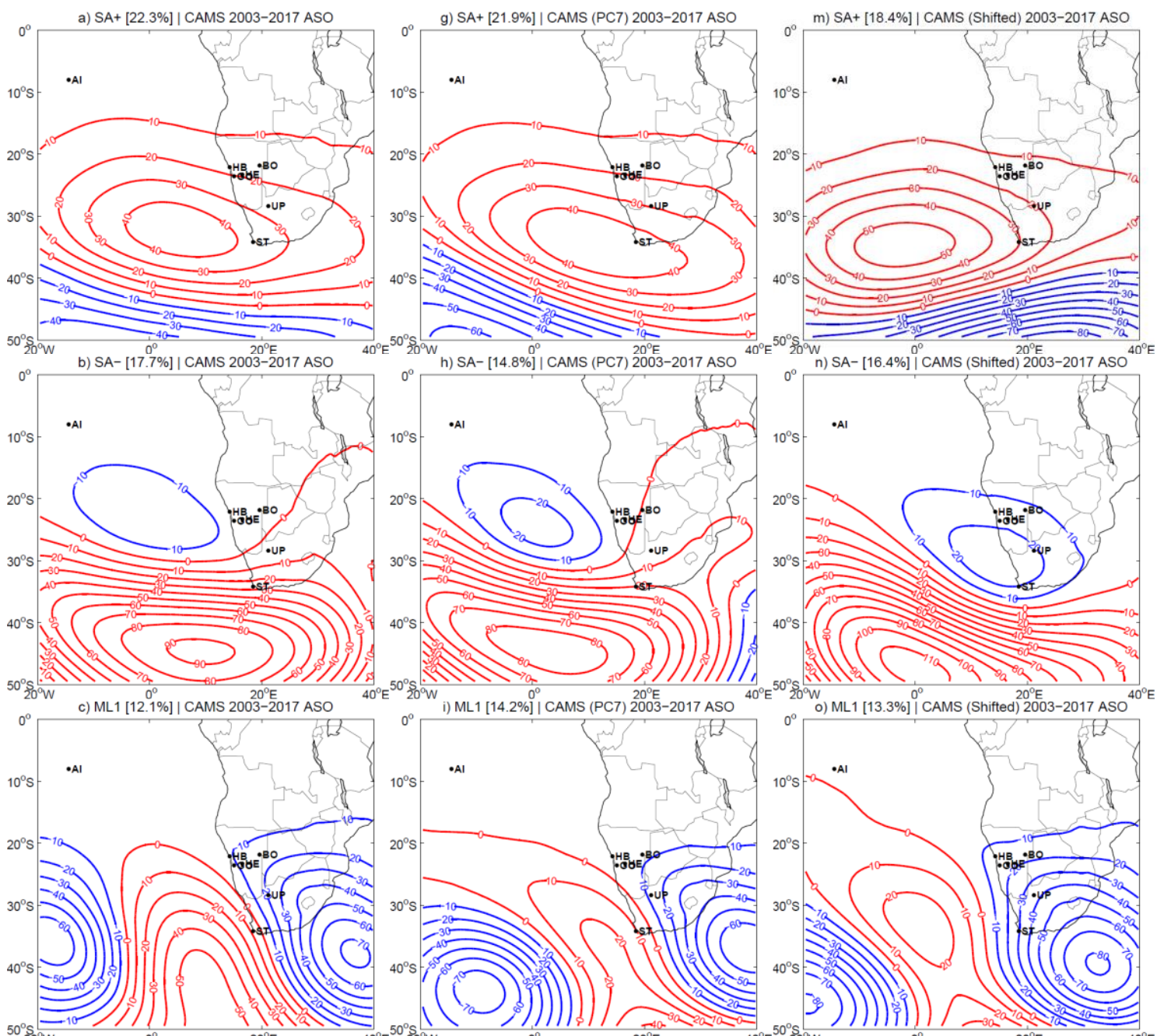

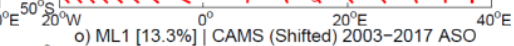
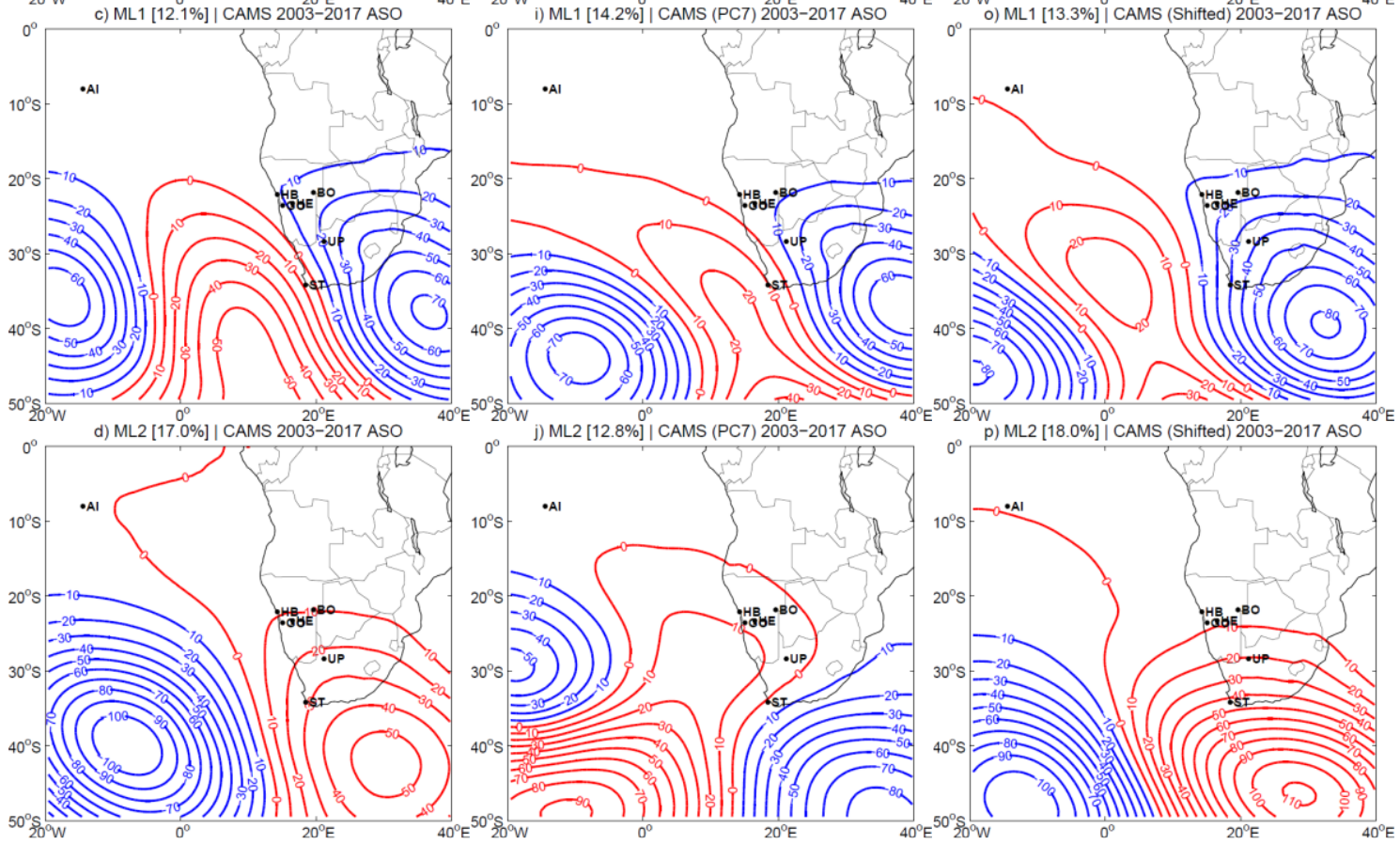

Figure S4. Anomaly patterns of CAMS geopotential height (m, contours) at $700 \mathrm{hPa}$ associated with $6 \mathrm{WRs}$ classified in ASO 2003-2017 (left panels) in the "control", (middle panels) "PC7", and (right panels) "shifted" classifications. Dots indicate the locations of the AERONET stations. 

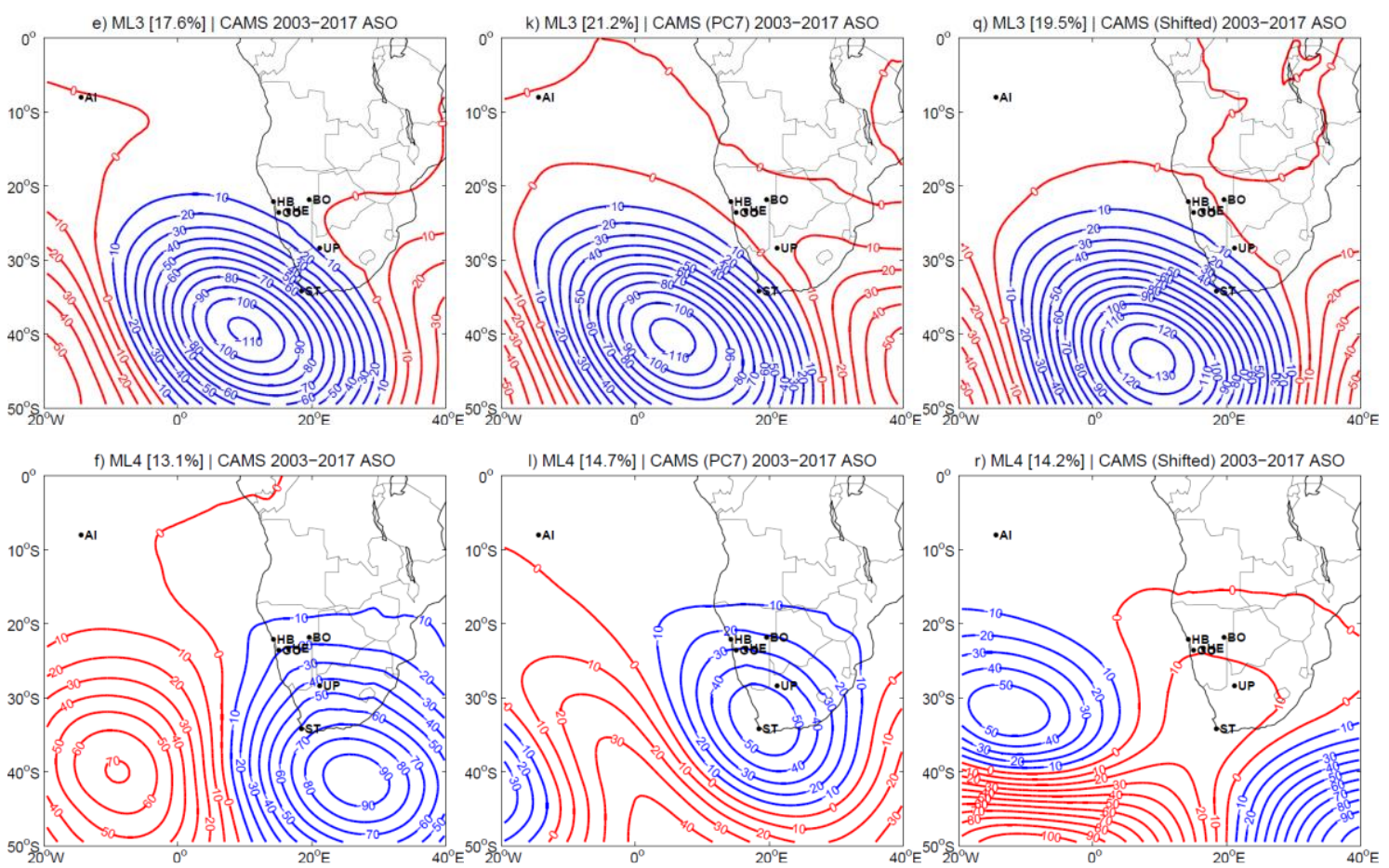

Figure S4. Continued.

a) CAMS WR persistence

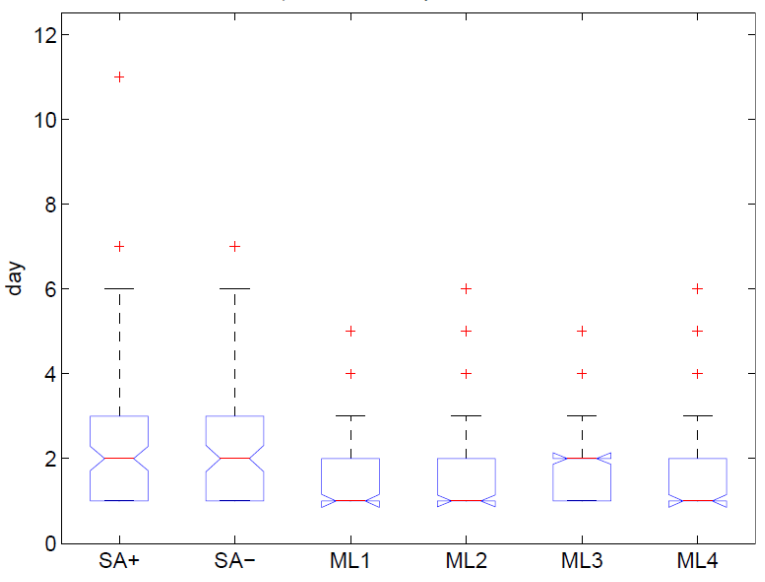

b) CAMS (PC7) WR persistence

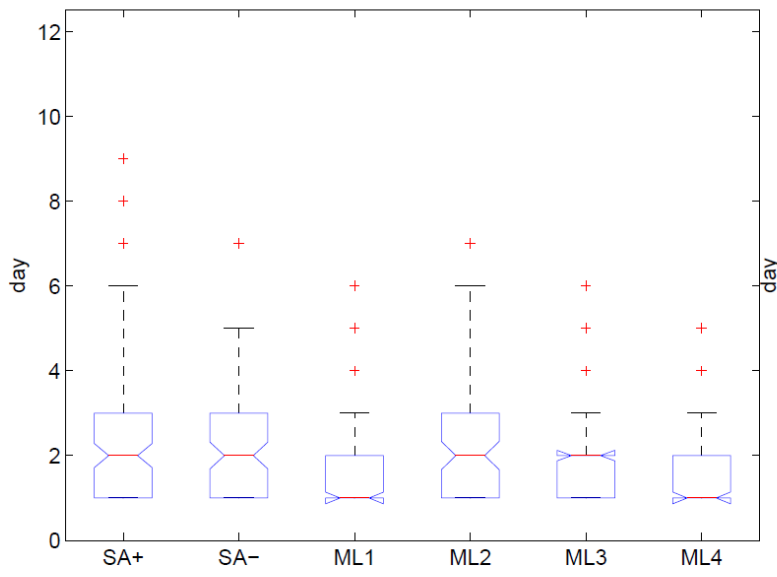

c) CAMS (Shifted) WR persistence

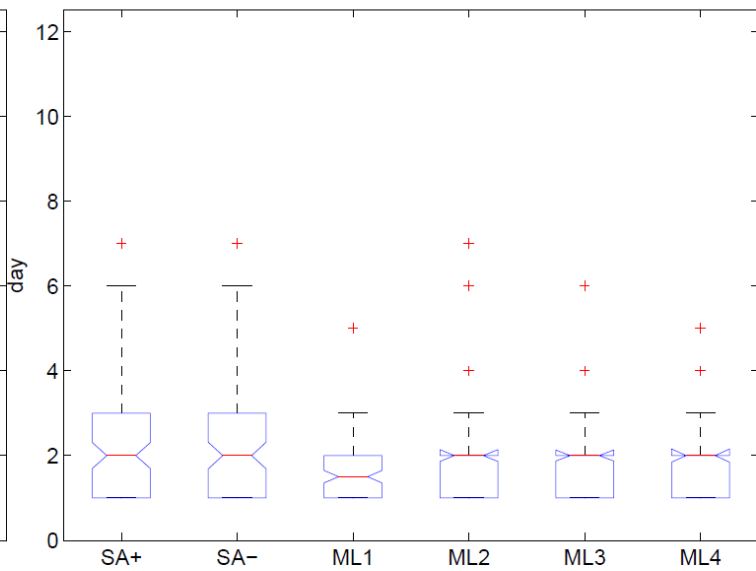

Figure S5. WR persistence in (a) "control", (b) "PC7" and (c) "Shifted" classifications, displayed as the distribution of the WR sequences. Red lines represent the median, boxes represent the interquartile range, whiskers extend up to the 1.5 of the interquartile range, outliers are displayed as red crosses. 
Table S1. WR transition rate in the "control" classification, computed as the percentage of transitions from a WR (rows) into the others (columns). By definition, the diagonal represents persistence. Transition rates above $1 / 6$, i.e. the threshold for non-random transitions, are reported in bold.

\begin{tabular}{|l|l|l|l|l|l|l|}
\hline WR & SA+ & SA- & ML1 & ML2 & ML3 & ML4 \\
\hline SA+ & $\mathbf{6 1}$ & 6 & 6 & 11 & 6 & 8 \\
\hline SA- & 10 & $\mathbf{5 9}$ & 5 & 10 & 8 & 7 \\
\hline ML1 & 8 & 14 & $\mathbf{3 9}$ & $\mathbf{2 8}$ & 8 & 3 \\
\hline ML2 & 12 & 5 & 3 & $\mathbf{4 6}$ & $\mathbf{3 1}$ & 1 \\
\hline ML3 & 12 & 9 & 4 & 5 & $\mathbf{4 5}$ & $\mathbf{2 4}$ \\
\hline ML4 & 12 & 13 & $\mathbf{2 8}$ & 2 & 3 & $\mathbf{4 0}$ \\
\hline
\end{tabular}

Table S2. WR transition rate in the "PC7" classification, computed as the percentage of transitions from a WR (rows) into the others (columns). By definition, the diagonal represents persistence. Transition rates above $1 / 6$, i.e. the threshold for non-random transitions, are reported in bold.

\begin{tabular}{|l|l|l|l|l|l|l|}
\hline WR & SA+ & SA- & ML1 & ML2 & ML3 & ML4 \\
\hline SA+ & $\mathbf{6 0}$ & 5 & 7 & 7 & 14 & 8 \\
\hline SA- & 15 & $\mathbf{5 3}$ & 4 & 3 & 9 & 16 \\
\hline ML1 & 14 & 10 & $\mathbf{3 5}$ & 7 & $\mathbf{3 1}$ & 3 \\
\hline ML2 & 10 & 13 & 14 & $\mathbf{5 0}$ & 11 & 2 \\
\hline ML3 & 8 & 8 & 3 & 12 & $\mathbf{4 6}$ & $\mathbf{2 2}$ \\
\hline ML4 & 10 & 7 & $\mathbf{3 3}$ & 5 & $\mathbf{7}$ & $\mathbf{3 7}$ \\
\hline
\end{tabular}

Table S3. WR transition rate in the "shifted" classification, computed as the percentage of transitions from a WR (rows) into the others (columns). By definition, the diagonal represents persistence. Transition rates above $1 / 6$, i.e. the threshold for non-random transitions, are reported in bold.

\begin{tabular}{|l|l|l|l|l|l|l|}
\hline WR & SA+ & SA- & ML1 & ML2 & ML3 & ML4 \\
\hline SA+ & $\mathbf{5 8}$ & 6 & 7 & 11 & 8 & 10 \\
\hline SA- & 8 & $\mathbf{5 7}$ & 13 & 12 & 3 & 7 \\
\hline ML1 & 12 & 2 & $\mathbf{3 9}$ & $\mathbf{2 2}$ & 15 & 10 \\
\hline ML2 & 10 & 8 & 3 & $\mathbf{4 9}$ & $\mathbf{2 6}$ & 5 \\
\hline ML3 & 13 & 11 & $\mathbf{1 7}$ & 3 & $\mathbf{4 6}$ & 11 \\
\hline ML4 & 3 & 14 & 7 & 13 & 14 & $\mathbf{4 8}$ \\
\hline
\end{tabular}

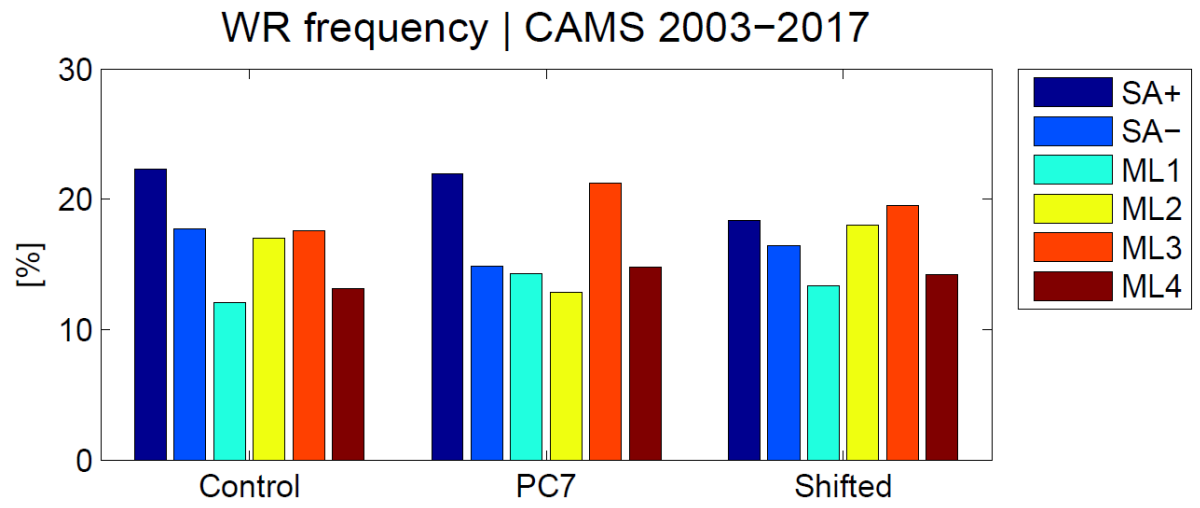

Figure S6. WR frequencies in the "control", "PC7" and "shifted" classifications. 


\section{S3. WR classification: 7 class partition and BBA transport characterisation}

The classification of the synoptic variability in the CAMS data performed by using the 7 class partition shows circulation patterns remarkably similar to the 6-class partition (see Section 3.1 and Fig. S7). Two synoptic patterns account for the oscillation of the pressure field in the South Atlantic. This synoptic variability is dominated by SA+ (South Atlantic positive), which occurs at a frequency of $18.9 \%$ and is characterised by a high pressure anomaly in the South Atlantic accompanied by a reinforcement of the midlatitude westerlies (Fig. S7a). Its symmetric counterpart is represented by SA- (South Atlantic negative), which occurs at a frequency of $15.2 \%$ and is characterised by a low pressure anomaly and a weaker westerly flow in the midlatitudes (Fig. S7b). The occurrence of these WRs is associated with the modulation of the BBA transport above the South Atlantic, and have limited impact over the continent. Four synoptic patterns represent the fingerprint of midlatitude disturbances propagating along the westerly flow (ML1-4), and account for $51.9 \%$ of the synoptic variability (Fig. S7c-g). These WRs are characterised by the longitudinal displacement of high-low pressure anomalies modulating the meridional circulation, which in turn drives the poleward BBA transport above the South Atlantic and southern Africa. In particular, ML3 favours the recirculation of BBA from the ocean towards Namibia and South Africa, leading to significant positive AOD anomalies above the continental stations (Fig. S7e), while ML2 pushes the BBA recirculation above the South Atlantic, resulting in significant positive $A O D$ anomalies above coastal stations, and inhibits the BBA transport towards the Indian Ocean (Fig. S7d). Conversely, ML1 and ML4 inhibit the BBA recirculation, leading to significant negative AOD anomalies the continental stations (Fig. S7cf). In addition to the 6-class partition, a circulation anomaly associated with a strengthening of the continental high $(\mathrm{CHI})$, resulting from the westward extension of the Mascarene High, is identified (Fig. S7g). This WR occurs at a frequency of $13.7 \%$. The occurrence of $\mathrm{CHI}$ increases the BBA transport above Ascension Island, but has little impact on continental stations, with the exception of the Simon's Town station, where the anomalous transport seems related to increased transport from South America by reinforced midlatitude westerlies (Chazette et al., 2019) (Fig. S7g). Transitions in SA+ and SA- circulation patterns are dominated by selftransitions ( $57 \%$ and $60 \%$, respectively, see Table $\$ 4)$, associated with short persistence (2-3 days, see Fig. S8). ML1-4 circulation patterns are characterised by self-transition rates below $50 \%$ and nonnegligible hetero-transitions (Table S4), associated with very short persistence (Fig. S8). The CHI circulation pattern shows intermediate features: self-transition rate above $50 \%$, non-negligible transitions towards ML3, and 2-3 day persistence (Table S4 and Fig. S8).

The circulation-to-environment (C2E) characterisation of the AOD AERONET station data (for details, see Section 2.4 and Table 1 in the main text) is presented in Fig. S9. At Ascension Island station, AOD anomalies during SA- show a preference for negative values (Fig. S9a). The significance of this characterisation is confirmed by the ANOVA with a level of confidence higher than $99 \%$. Just south of the source region, AOD anomalies in Bonanza do not show any preference for different WRs, as also confirmed by ANOVA ( $p=0.37$ ) indicating no significance for this characterisation (Fig. S9b). Namibian stations in Gobabeb, Henties Bay and HESS show negative AOD anomalies associated with ML1 and ML4, while positive AOD anomalies are associated with SA- (Fig. S9c-f). For these stations, the ANOVA indicates that the characterisation is significant with a level of confidence higher than $99 \%$. The continental station in Upington shows positive anomalies associated with ML3, while ML4 leads to negative anomalies (Fig. S9h). The ANOVA indicates that the characterisation is significant $(p=0.04)$ in this location. In South Africa, the southernmost station in Simon's Town shows a poor WR characterisation $(p=0.08)$ and no significant anomalies are associated with any WR (Fig. S9g).

The environment-to-circulation (E2C) characterisation of the AOD AERONET station data (for details, see Section 2.4 and Table 1 in the main text) is presented in Fig. S10. In Ascension Island, positive 
AOD anomalies are accompanied by an increase in the occurrence of ML3 and ML4, while negative anomalies are associated with more frequent SA- and ML1 (Fig. S10a). The Bonanza station does not show any significant change in the WR occurrence (Fig. S10b). Namibian stations in Gobabeb, Henties Bay and HESS show positive AOD anomalies associated with more frequent SA- (Fig. S10c-f). In Upington, increased occurrence of SA- and ML3 is associated with positive AOD anomalies, while more frequent SA- and ML4 are associated with negative anomalies (Fig. S1Oh). In Simon's Town, increased occurrence of SA-, ML2 and CHI is associated with positive AOD anomalies (Fig. S10g).
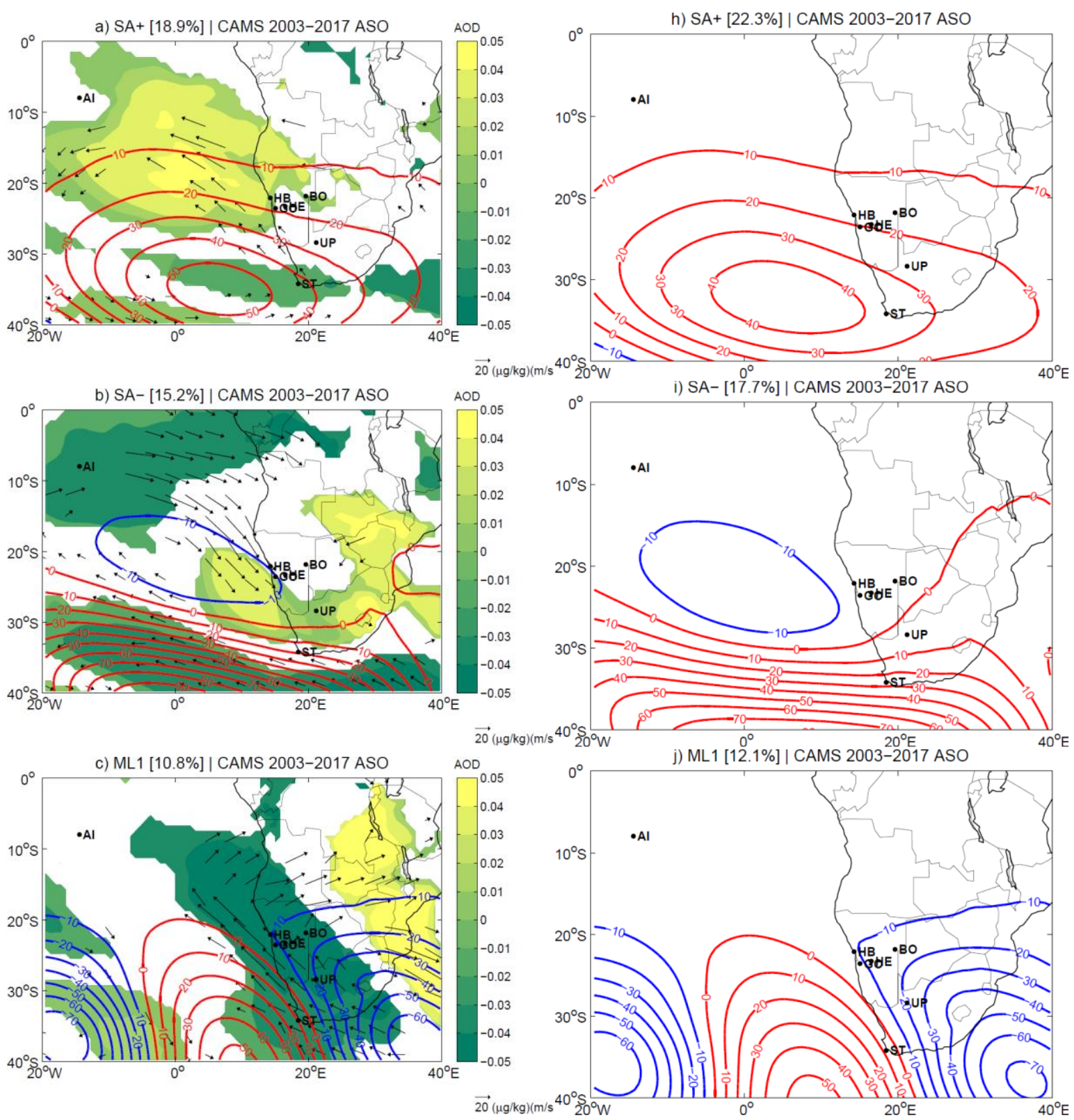

Figure S7. In the left panels: anomaly patterns of CAMS geopotential height ( $\mathrm{m}$, contours), AOD at $550 \mathrm{~nm}$ (shadings) and BBA transport $((\mu \mathrm{g} / \mathrm{kg})(\mathrm{m} / \mathrm{s})$, arrows) at $700 \mathrm{hPa}$ associated with $7 \mathrm{WRs}$ classified from the geopotential height at $700 \mathrm{hPa}$ in ASO 2003-2017. In the right panels: anomaly patterns of CAMS geopotential height ( $\mathrm{m}$, contours), associated with 6 WRs classified from the geopotential height at $700 \mathrm{hPa}$ in ASO 20032017. Dots indicate the locations of the AERONET stations. Frequency of the WRs is indicated in brackets; only values significant at $95 \%$ level of confidence for a Student's t-test are displayed. 

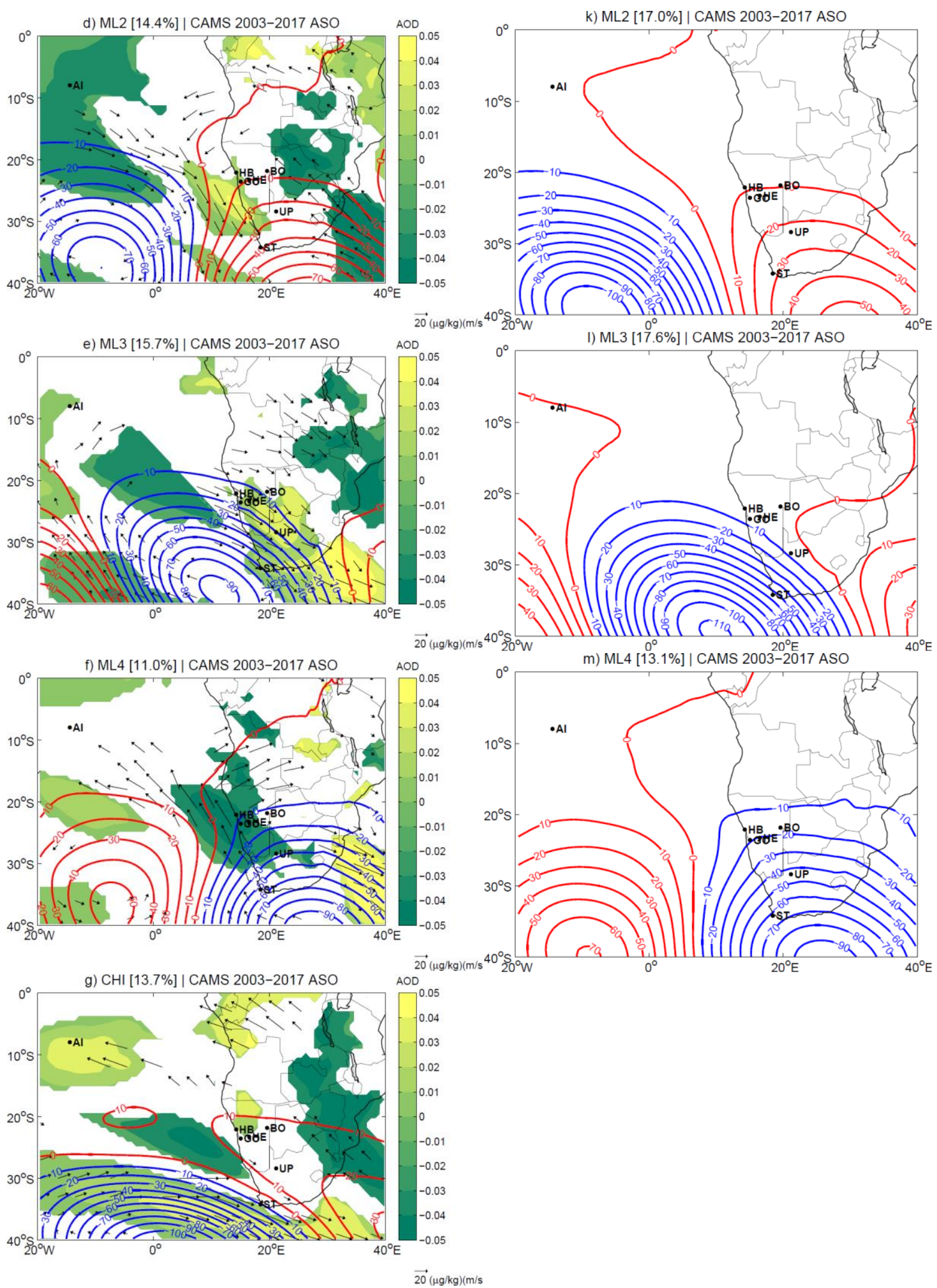

Figure S7. Continued. 


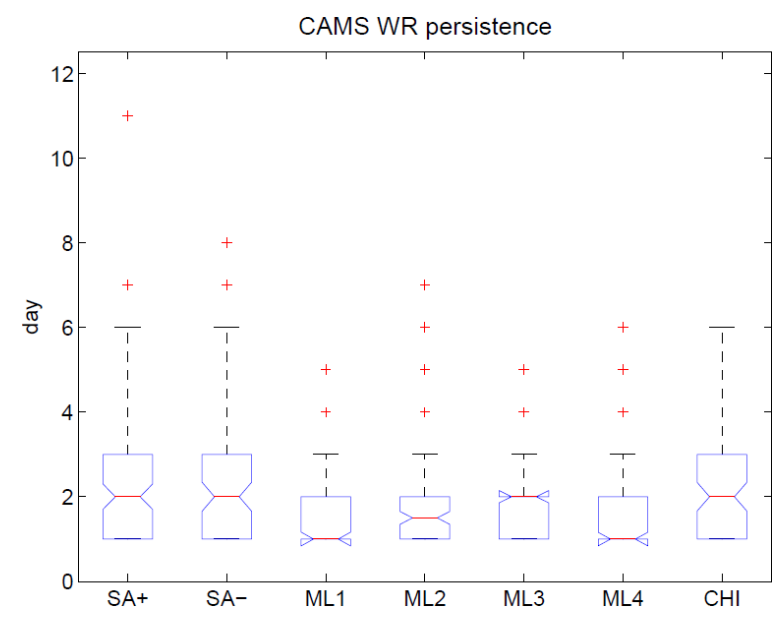

Figure S8. WR persistence, displayed as the distribution of the WR sequences. Red lines represent the median, boxes represent the interquartile range, whiskers extend up to the 1.5 of the interquartile range, outliers are displayed as red crosses.

a) WRs vs AERONET BB AOD 500nm | Al [612] $(p<0.01)$

b) WRs vs AERONET BB AOD 500nm | BO [126] $(p=0.37)$
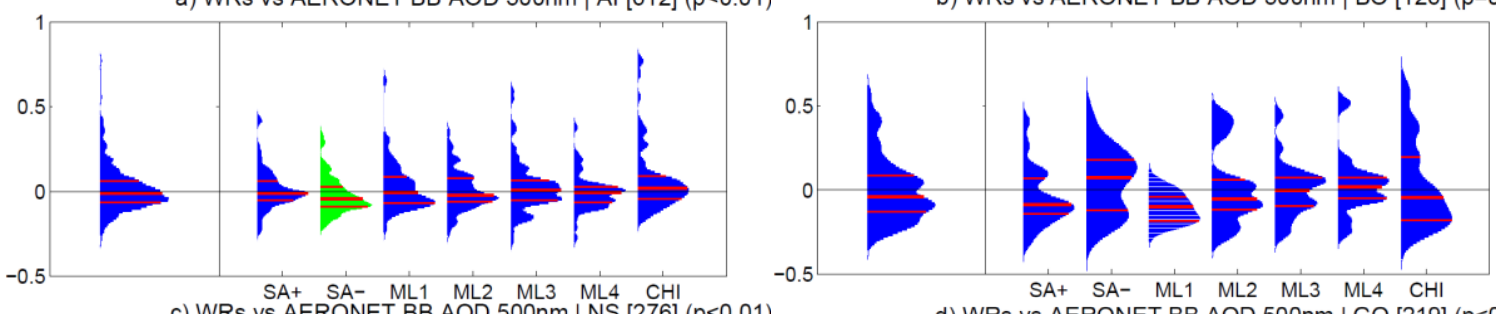

d) WRs vs AERONET BB AOD $500 \mathrm{~nm}$ | GO [219] $(p<0.01)$

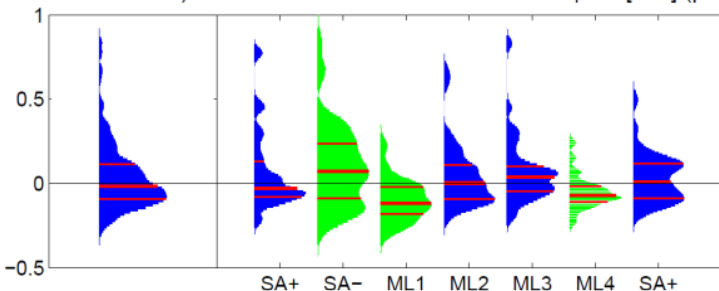

e) WRs vs AERONET BB AOD $500 \mathrm{~nm}$ | HB [139] $(\mathrm{p}<0.01)$

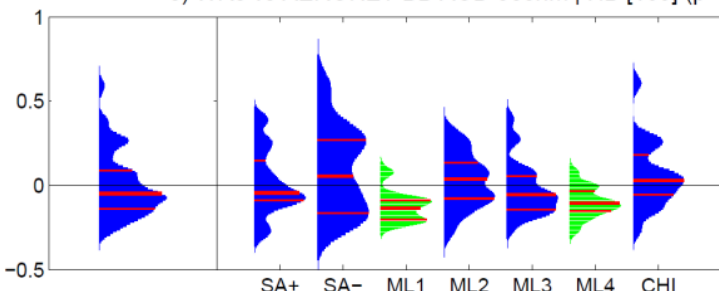

g) WRs vs AERONET BB AOD $500 \mathrm{~nm}$ | ST [111] $(\mathrm{p}=0.08)$
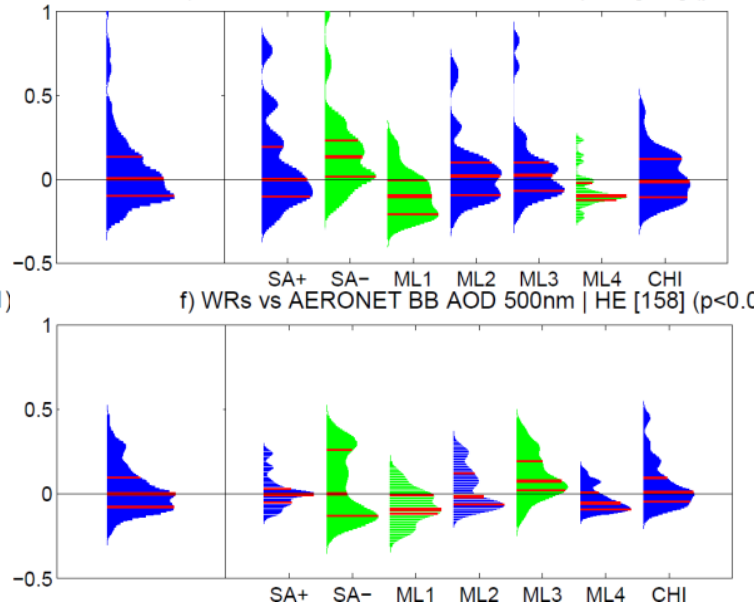

h) WRs vs AERONET BB AOD $500 \mathrm{~nm}$ | UP [127] $(\mathrm{p}=0.04)$
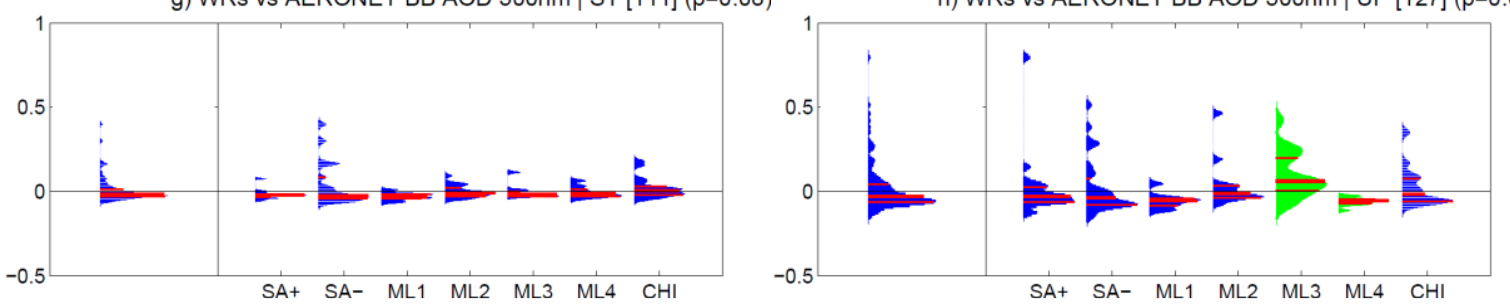

Figure S9. Circulation to environment characterisation: distributions of the AOD anomalies at $500 \mathrm{~nm}$ at the AERONET stations, and as a function of the WRs. Probability density functions are estimated by using a normal kernel density; red lines represent 25th, 50th and 75th percentiles. Anomaly distributions significantly different from the climatological sample are displayed in green ( $p$-values of the Kolmogorov-Smirnov test used to assess the significance of the differences are reported in Table S5). In titles, the number of available daily observations and the p-value of the ANOVA used to assess the WR characterisation are reported in brackets. 
Table S4. WR transition rate in the CAMS reanalysis, computed as the percentage of transitions from a WR (rows) into the others (columns). By definition, the diagonal represents persistence. By definition, the diagonal represents persistence. Transition rates above 1/7, i.e. the threshold for non-random transitions, are reported in bold.

\begin{tabular}{|l|l|l|l|l|l|l|l|}
\hline WR & SA+ & SA- & ML1 & ML2 & ML3 & ML4 & CHI \\
\hline SA+ & $\mathbf{5 7}$ & $\mathbf{7}$ & 7 & 10 & 3 & 8 & 7 \\
\hline SA- & 12 & $\mathbf{6 0}$ & 3 & 11 & 10 & 3 & 0 \\
\hline ML1 & 7 & 6 & $\mathbf{3 8}$ & $\mathbf{2 9}$ & 6 & 1 & 13 \\
\hline ML2 & 8 & 5 & 2 & $\mathbf{4 6}$ & $\mathbf{1 8}$ & 2 & $\mathbf{2 0}$ \\
\hline ML3 & 6 & $\mathbf{1 5}$ & 8 & 3 & $\mathbf{4 6}$ & $\mathbf{1 9}$ & 3 \\
\hline ML4 & $\mathbf{1 6}$ & 11 & $\mathbf{2 8}$ & 3 & 3 & $\mathbf{3 6}$ & 3 \\
\hline CHI & 10 & 0 & 2 & 3 & $\mathbf{2 0}$ & 12 & $\mathbf{5 4}$ \\
\hline
\end{tabular}

a) Al [612]

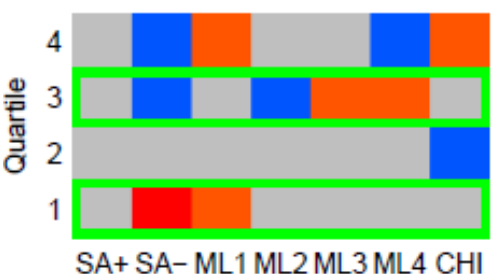

c) NS [276]

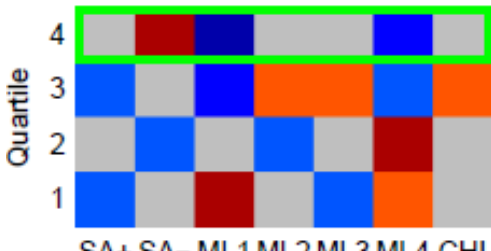

e) HB [139]

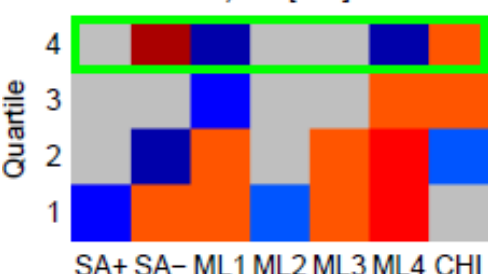

g) ST [111]

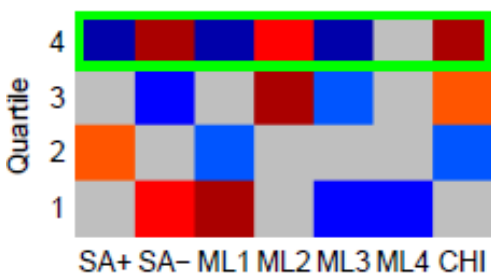

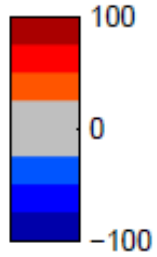
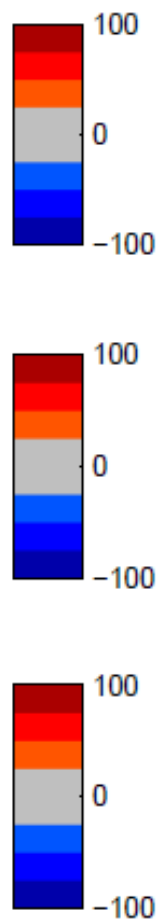

b) $\mathrm{BO}[126]$

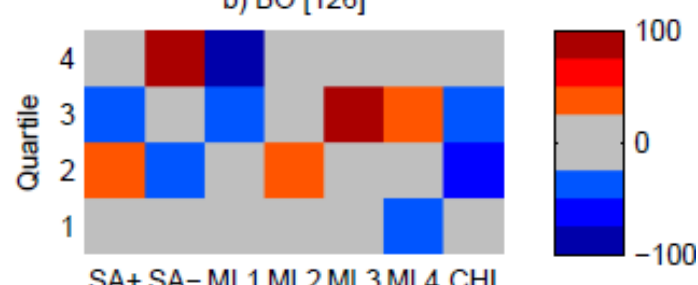

d) GO [219]

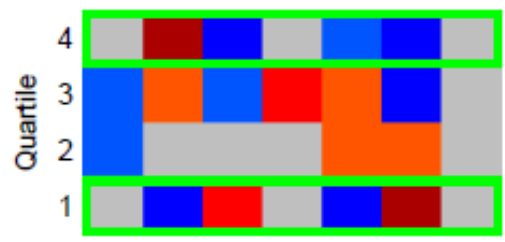

SA+SA-ML1 ML2 ML3 ML4 CHI

f) HE [158]
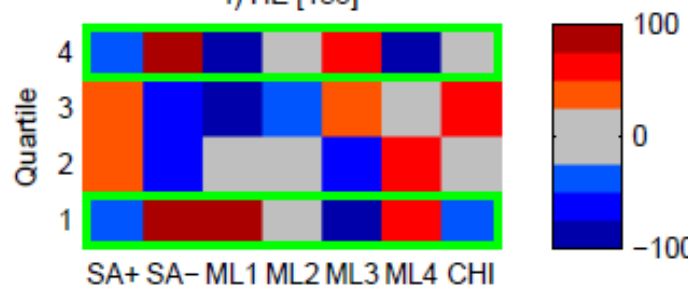

h) UP [127]

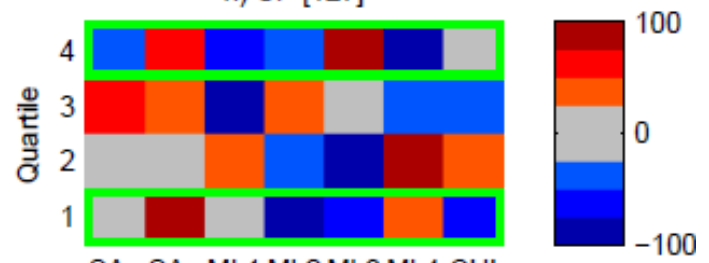

Figure S10. Environment to circulation characterisation: WR frequency anomaly as a function of the quartiles of the AOD anomalies at $500 \mathrm{~nm}$ at the AERONET stations. Values represent percentage changes relative to climatological frequencies. Green boxes highlight significant changes in the WR frequencies, i.e. frequency anomalies exceeding the critical threshold (12.59) for the chi-squared statistics with 5 degrees of freedom at 95\% level of confidence (chi-squared statistics are reported in Table S8). In brackets, the number of available daily observations are indicated. 

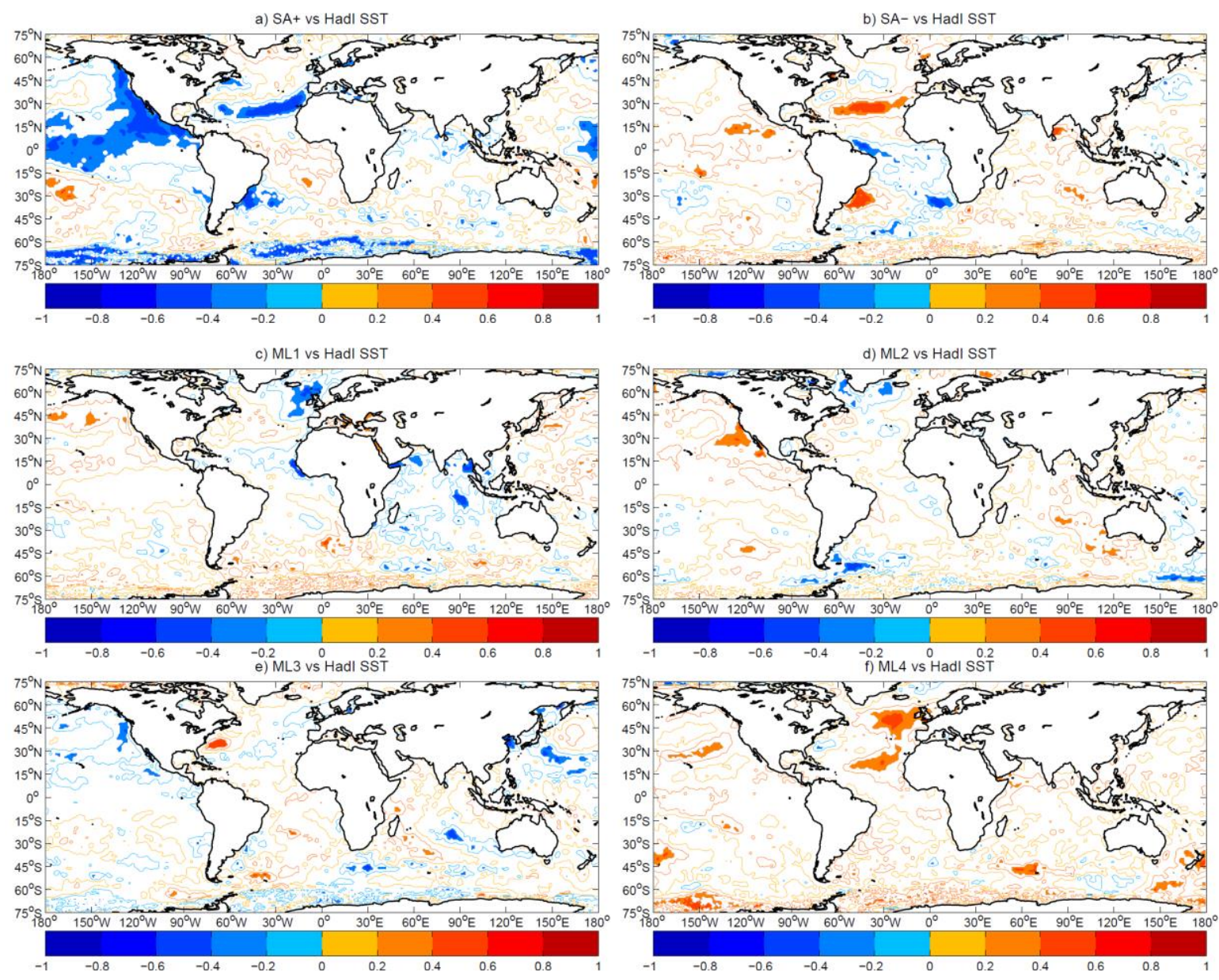

Figure S11. Interannual correlation over the period 1981-2020: ERA5 WR frequency vs HadI SST in ASO. Shadings display significant correlations at $95 \%$ level of confidence. Time series are detrended and standardised. 

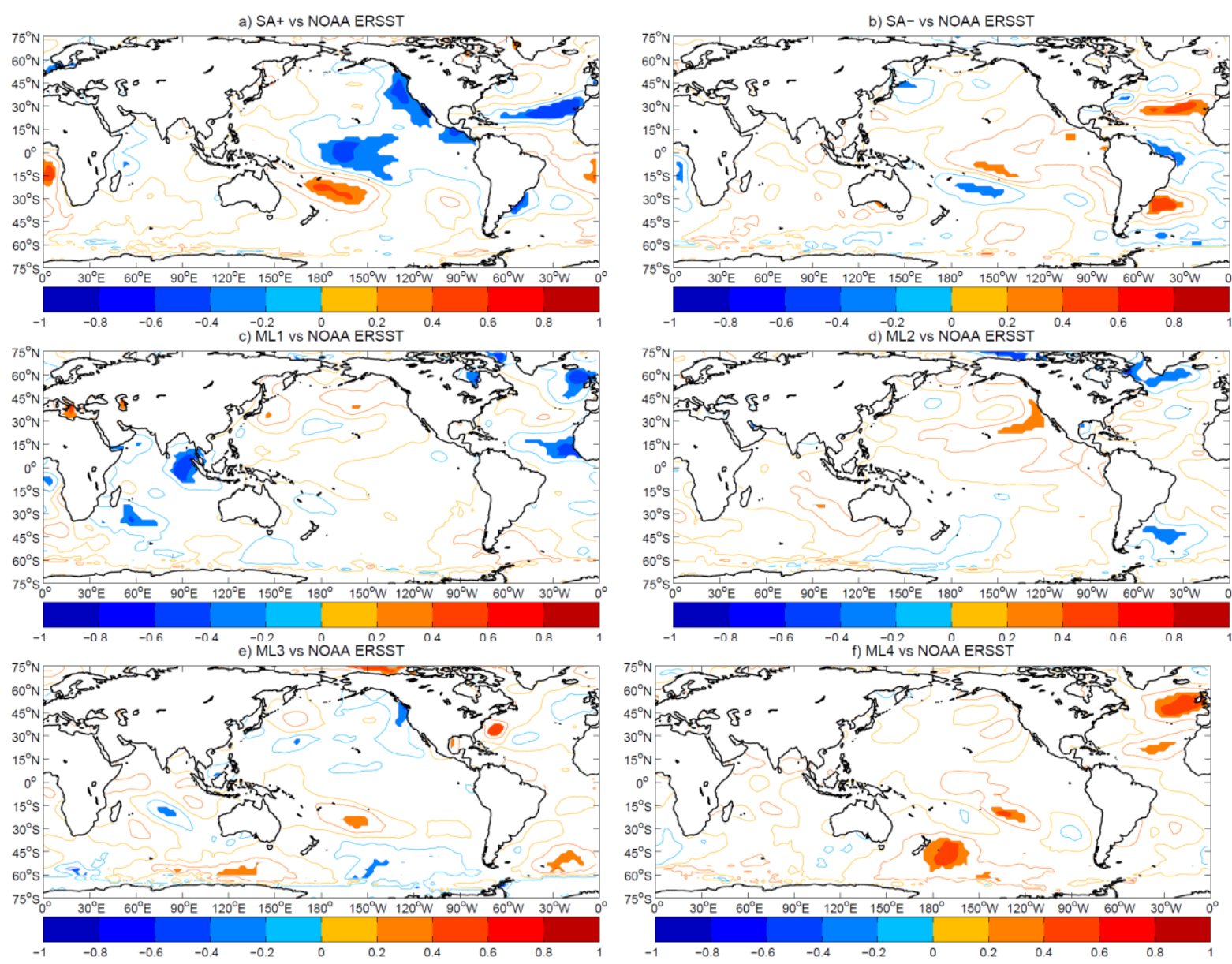

Figure S12. Interannual correlation over the period 1981-2020: ERA5 WR frequency vs NOAA ERSST in ASO. Shadings display significant correlations at $95 \%$ level of confidence. Time series are detrended and standardised.

\section{S5. Synoptic characterisation of aerosol optical depth in-situ observations: Tables}

Table S5. 6-WR circulation-to-environment characterisation of the AOD anomalies at the AERONET stations: Pvalues of ANOVA and Kolmogorov-Smirnov tests. Values lower than 0.05 are reported in bold.

\begin{tabular}{|l|l|l|l|l|l|l|l|}
\hline Station & ANOVA & SA + & SA- & ML1 & ML2 & ML3 & ML4 \\
\hline Ascension Island (AI) & $\mathbf{0 . 0 1}$ & 0.23 & $\mathbf{0 . 0 4}$ & 0.91 & 0.89 & 0.07 & 0.27 \\
\hline Bonanza (BO) & 0.07 & 0.67 & 0.35 & 0.30 & 0.75 & 0.89 & $\mathbf{0 . 0 1}$ \\
\hline Namibian Stations (NS) & $<\mathbf{0 . 0 1}$ & 0.71 & $\mathbf{0 . 0 3}$ & $<\mathbf{0 . 0 1}$ & 0.89 & 0.06 & 0.31 \\
\hline Gobabeb (GO) & $<\mathbf{0 . 0 1}$ & 0.89 & $<\mathbf{0 . 0 1}$ & $\mathbf{0 . 0 1}$ & 0.98 & 0.54 & 0.07 \\
\hline Henties Bay (HB) & $<\mathbf{0 . 0 1}$ & 0.77 & 0.17 & $<\mathbf{0 . 0 1}$ & 0.49 & 0.69 & 0.12 \\
\hline HESS (HE) & $<\mathbf{0 . 0 1}$ & 0.26 & 0.35 & $<\mathbf{0 . 0 1}$ & 0.71 & $<0.01$ & 0.93 \\
\hline Simon's Town IMT (ST) & 0.09 & 0.26 & 0.60 & 0.26 & 0.13 & 0.91 & 0.87 \\
\hline Upington (UP) & $<\mathbf{0 . 0 1}$ & 0.86 & 0.22 & $\mathbf{0 . 0 3}$ & 0.63 & $<\mathbf{0 . 0 1}$ & $\mathbf{0 . 0 2}$ \\
\hline
\end{tabular}


Table S6. 6-WR environment-to-circulation characterisation of the AOD anomalies at the AERONET stations: chi-squared statistics for each quartile (Q1-4). Values exceeding 11.07, i.e. the critical threshold for the chisquared distribution with 5 degrees of freedom at $95 \%$ level of confidence, are reported in bold.

\begin{tabular}{|l|l|l|l|l|}
\hline Station & Q1 & Q2 & Q3 & Q4 \\
\hline Ascension Island (AI) & 8.05 & 2.99 & $\mathbf{1 1 . 1 9}$ & 9.31 \\
\hline Bonanza (BO) & 3.91 & 2.82 & 1.28 & 7.35 \\
\hline Namibian Stations (NC) & $\mathbf{1 4 . 5 0}$ & 3.58 & 5.09 & $\mathbf{1 8 . 4 9}$ \\
\hline Gobabeb (GO) & $\mathbf{1 2 . 2 9}$ & 1.99 & 10.68 & $\mathbf{1 7 . 0 3}$ \\
\hline Henties Bay (HB) & 6.45 & 6.98 & 6.16 & $\mathbf{1 1 . 4 9}$ \\
\hline HESS (HE) & $\mathbf{1 5 . 0 4}$ & 7.99 & $\mathbf{1 2 . 5 9}$ & $\mathbf{1 2 . 1 6}$ \\
\hline Simon's Town IMT (ST) & 5.93 & 1.79 & 11.04 & $\mathbf{1 7 . 3 0}$ \\
\hline Upington (UP) & $\mathbf{1 4 . 2 9}$ & 10.14 & 3.86 & $\mathbf{2 5 . 2 3}$ \\
\hline
\end{tabular}

Table S7. 7-WR circulation-to-environment characterisation of the AOD anomalies at the AERONET stations: Pvalues of ANOVA and Kolmogorov-Smirnov tests. Values lower than 0.05 are reported in bold.

\begin{tabular}{|l|l|l|l|l|l|l|l|l|}
\hline Station & ANOVA & SA+ & SA- & ML1 & ML2 & ML3 & ML4 & CHI \\
\hline Ascension Island (AI) & $<\mathbf{0 . 0 1}$ & 0.52 & $\mathbf{0 . 0 1}$ & 0.78 & 0.90 & 0.51 & 0.23 & 0.16 \\
\hline Bonanza (BO) & 0.37 & 0.42 & 0.18 & 0.13 & 0.95 & 0.89 & 0.27 & 0.81 \\
\hline Namibian Stations (NS) & $<\mathbf{0 . 0 1}$ & 0.88 & $\mathbf{0 . 0 4}$ & $<\mathbf{0 . 0 1}$ & 0.97 & 0.21 & $<\mathbf{0 . 0 1}$ & 0.81 \\
\hline Gobabeb (GO) & $<\mathbf{0 . 0 1}$ & 0.75 & $<\mathbf{0 . 0 1}$ & $\mathbf{0 . 0 3}$ & 0.98 & 0.64 & $<\mathbf{0 . 0 1}$ & 0.88 \\
\hline Henties Bay (HB) & $<\mathbf{0 . 0 1}$ & 0.91 & 0.13 & $\mathbf{0 . 0 1}$ & 0.54 & 0.94 & $\mathbf{0 . 0 3}$ & 0.21 \\
\hline HESS (HE) & $<\mathbf{0 . 0 1}$ & 0.44 & $\mathbf{0 . 0 3}$ & $\mathbf{0 . 0 5}$ & 0.60 & $<\mathbf{0 . 0 1}$ & 0.13 & 0.50 \\
\hline Simon's Town IMT (ST) & 0.08 & 0.18 & 0.52 & 0.11 & 0.48 & 0.58 & 0.97 & 0.17 \\
\hline Upington (UP) & $\mathbf{0 . 0 4}$ & 0.90 & 0.40 & 0.07 & 0.13 & $<\mathbf{0 . 0 1}$ & $<\mathbf{0 . 0 1}$ & 0.87 \\
\hline
\end{tabular}

Table S8. 7-WR environment-to-circulation characterisation of the AOD anomalies at the AERONET stations: chi-squared statistics for each quartile (Q1-4). Values exceeding 12.59 , i.e. the critical threshold for the chisquared distribution with 5 degrees of freedom at $95 \%$ level of confidence, are reported in bold.

\begin{tabular}{|l|l|l|l|l|}
\hline Station & Q1 & Q2 & Q3 & Q4 \\
\hline Ascension Island (AI) & $\mathbf{1 4 . 0 1}$ & 4.87 & $\mathbf{1 3 . 0 4}$ & 11.69 \\
\hline Bonanza (BO) & 1.28 & 3.28 & 6.68 & 9.80 \\
\hline Namibian Stations (NS) & 11.38 & 8.61 & 8.63 & $\mathbf{2 7 . 3 0}$ \\
\hline Gobabeb (GO) & $\mathbf{1 4 . 5 5}$ & 3.56 & 9.01 & $\mathbf{2 5 . 4 3}$ \\
\hline Henties Bay (HB) & 5.44 & 6.83 & 3.91 & $\mathbf{1 7 . 1 2}$ \\
\hline HESS (HE) & $\mathbf{1 6 . 3 5}$ & 8.09 & 9.61 & $\mathbf{1 3 . 6 3}$ \\
\hline Simon's Town IMT (ST) & 8.10 & 2.01 & 4.62 & $\mathbf{1 9 . 0 9}$ \\
\hline Upington (UP) & $\mathbf{1 7 . 1 3}$ & 9.08 & 7.80 & $\mathbf{1 5 . 6 4}$ \\
\hline
\end{tabular}

\section{References}

Chazette, P., Flamant, C., Totems, J., Gaetani, M., Smith, G., Baron, A., Landsheere, X., Desboeufs, K., Doussin, J.-F. and Formenti, P.: Evidence of the complexity of aerosol transport in the lower troposphere on the Namibian coast during AEROCLO-sA, Atmos. Chem. Phys., 19(23), 14979-15005, doi:10.5194/acp-19-14979-2019, 2019.

Michelangeli, P. A., Vautard, R. and Legras, B.: Weather regimes: recurrence and quasi stationarity, J. Atmos. Sci., 52(8), 1237-1256, doi:10.1175/1520-0469(1995)052<1237:WRRAQS>2.0.CO;2, 1995. 
Widlansky, M. J., Webster, P. J. and Hoyos, C. D.: On the location and orientation of the South Pacific Convergence Zone, Clim. Dyn., 36(3), 561-578, doi:10.1007/s00382-010-0871-6, 2011.

van der Wiel, K., Matthews, A. J., Stevens, D. P. and Joshi, M. M.: A dynamical framework for the origin of the diagonal South Pacific and South Atlantic Convergence Zones, Q. J. R. Meteorol. Soc., 141(691), 1997-2010, doi:10.1002/qj.2508, 2015. 